\title{
A Bioreactor Designed for Restricting Oversize of Aerobic Granular Sludge
}

\author{
Hongbo Feng ${ }^{1}{ }^{\oplus}$, Honggang Yang ${ }^{2}$, Jianlong Sheng ${ }^{1}$, Zengrui Pan ${ }^{1}$ and Jun $\mathrm{Li}^{1, *}$ \\ 1 Key Laboratory of Microbial Technology for Industrial Pollution Control of Zhejiang Province, College of \\ Environment, Zhejiang University of Technology, Hangzhou 310014, China; hongbo_feng@163.com (H.F.); \\ sj119970316@163.com (J.S.); pzr19970701@163.com (Z.P.) \\ 2 Jinhua Municipal Design Institute Company Limited, Jinhua 321017, China; h.g.yang@foxmail.com \\ * Correspondence: tanweilijun@zjut.edu.cn
}

check for updates

Citation: Feng, H.; Yang, H.; Sheng, J.; Pan, Z.; Li, J. A Bioreactor Designed for Restricting Oversize of Aerobic Granular Sludge. Processes 2021, 9 , 374. https://doi.org/10.3390/ pr9020374

Academic Editors: Francesca Raganati, Alessandra Procentese and Bipro R. Dhar

Received: 27 November 2020

Accepted: 12 February 2021

Published: 18 February 2021

Publisher's Note: MDPI stays neutral with regard to jurisdictional claims in published maps and institutional affiliations.

Copyright: (c) 2021 by the authors. Licensee MDPI, Basel, Switzerland. This article is an open access article distributed under the terms and conditions of the Creative Commons Attribution (CC BY) license (https:// creativecommons.org/licenses/by/ $4.0 /)$.

\begin{abstract}
Aerobic granular sludge (AGS) with oversized diameter commonly affects its stability and pollutant removal. In order to effectively restrict the particle size of AGS, a sequencing batch reactor (SBR) with a spiny aeration device was put forward. A conventional SBR (R1) and an SBR (R2) with the spiny aeration device treating tannery wastewater were compared in the laboratory. The result indicates that the size of the granular sludge from R2 was smaller than that from R1 with sludge granulation. The spines and air bubbles could effectively restrict the particle size of AGS by collision and abrasion. Nevertheless, there was no significant change in mixed liquor suspended solids (MLSS) and the sludge volume index (SVI) in either bioreactors. The removal (\%) of chemical oxygen demand (COD) and ammonia nitrogen $\left(\mathrm{NH}_{4}{ }^{+}-\mathrm{N}\right)$ in these two bioreactors did not differ from each other greatly. The analysis of biological composition displays that the proportion of Proteobacteria decreased slightly in R2. The X-ray fluorescence (XRF) analysis revealed less accumulation of Fe and Ca in smaller granules. Furthermore, a pilot-scale SBR with a spiny aeration device was successfully utilized to restrict the diameter of granules at about $300 \mu \mathrm{m}$.
\end{abstract}

Keywords: aerobic granular sludge; oversize; diameter; bioreactor; wastewater

\section{Introduction}

Aerobic granular sludge (AGS) is a biological aggregate which is generally defined as more than $90 \%$ of sludge with particle size greater than $200 \mu \mathrm{m}[1,2]$. It was first cultured by Mishima et al. [3] in an aerobic upflow sludge blanket (AUSB) with pure oxygen aeration in 1911. AGS has excellent properties such as compact microbial structure, good settling performance, and tolerance to high organic loading [1,4]. Therefore, AGS has been evaluated for treatment of various industrial wastewaters such as textile [5], rubber [6], brewery [7], and petroleum [8] wastewater. Moreover, AGS has been used in municipal sewage, and it shows better performance than traditional activated sludge. The AGS process is considered as a promising and alternative technology for wastewater treatment. However, most of the reported AGS is still at the lab or pilot-scale [9,10], with only a few reported cases at full-scale [11,12].

The stability of AGS is one of the main reasons limiting its wide practical application [13]. Besides, the particle size of AGS is one of the major factors which exert influence on its stability. The selective pressure is necessary for the formation of AGS, generally in the way of removing the flocculent sludge with poor settling performance and retaining the sludge with good settling performance by regulating the settling time. The sludge with larger particle size shows better settling performance. The average particle size of AGS in the reactor increases gradually under selective pressure. Granular sludge cultivated by Jungles et al. [14] was about $3500 \mu \mathrm{m}$ in diameter. Farooqi and Farrukh [15] cultivated granular sludge of an average $2000-4000 \mu \mathrm{m}$ in diameter in SBR with different selective pressures. The results showed that with the particle size increasing, the resistance of mass 
which transfers from the surface to the interior would increase so that the anaerobic zone would expand, and the lack of nutrients in the interior would further lead to the disintegration of the sludge particles, and finally to the failure of operation [16]. Toh et al. [17] separated the AGS with different particle sizes in SBR to study its properties. They drew the conclusion that the most economical and effective particle size range is 1000-3000 $\mu \mathrm{m}$. The effective restriction of the particle size of granular sludge is of great significance to the engineering application of it.

A great number of studies have been conducted on the physicochemical properties and treatment effects of AGS with different particle sizes [18,19]. However, methods about restricting particle size have rarely been reported. A method for restricting the particle size of AGS is sieving. Long et al. [20] manually sieved to obtain the 2000-3000 $\mu \mathrm{m}$ granular sludge and returned it to the reactor. However, this is not easy to do in engineering applications. When the AGS was oversize, the efficiency of mass transfer would decrease and the stability would become worse. Therefore, there is a necessity to find an effective and convenient method to restrict particle size of AGS. A bioreactor which can restrict the particle size of AGS was proposed in this experiment. The spiny aeration device was adopted in this bioreactor to restrict the particle size of AGS to tackle the instability caused by its oversize diameter. The spiny aeration device could effectively restrict the particle size of AGS without additional equipment.

\section{Materials and Methods}

\subsection{Inoculated Sludge and Wastewater}

The inoculated sludge was obtained from the aerobic tank of a tannery wastewater treatment plant in Haining, Zhejiang Province. The mixed liquor suspended solids (MLSS) of the inoculated sludge were about $8300 \mathrm{mg} / \mathrm{L}$ and the sludge volume index (SVI) with 30 min settling time $\left(\mathrm{SVI}_{30}\right)$ was about $75 \mathrm{~mL} / \mathrm{g}$. The influent water was taken from pretreated tannery wastewater. The main parameters of the wastewater were as follows: pH 6-8, chemical oxygen demand (COD) 550-800 mg/L, ammonia nitrogen $\left(\mathrm{NH}_{4}{ }^{+}-\mathrm{N}\right)$ $105-160 \mathrm{mg} / \mathrm{L}$, suspended solids (SS) $60-120 \mathrm{mg} / \mathrm{L}$, and total phosphorous (TP) $1-4 \mathrm{mg} / \mathrm{L}$.

\subsection{Experimental Set-Up and Operation}

\subsubsection{Lab-Scale Sequencing Batch Reactors}

Aerobic granular sludge treating tannery wastewater was obtained in two lab-scale sequencing batch reactors (SBRs). The conventional aeration device was used in R1 and the spiny aeration device made of plastic material was used in R2 (Figure 1). The SBRs each had a diameter of $20 \mathrm{~cm}$ and a working volume of $11 \mathrm{~L}$ with a volumetric exchange ratio of $7 / 11$. One period was $12 \mathrm{~h}$ and including the following procedures, influent $(5 \mathrm{~min})$, aeration $(11 \mathrm{~h})$, settling $(5 \mathrm{~min})$, drainage $(20 \mathrm{~min})$, and standing ( $30 \mathrm{~min})$. The lab-scale reactors were operated for a total period of 70 days. The aeration volume was controlled at about $0.7 \mathrm{~m}^{3} / \mathrm{h}$. The laboratory temperature was $15 \sim 30{ }^{\circ} \mathrm{C}$ during the whole period. It is worth noting that bioreactors for wastewater treatment would usually be exposed to temperature differences in a real-life scenario (Table S1), so the temperature in the lab was not constant artificially. But R1 and R2 had the same temperature. The SBRs were cleaned weekly to prevent biofilm formation on the wall. 


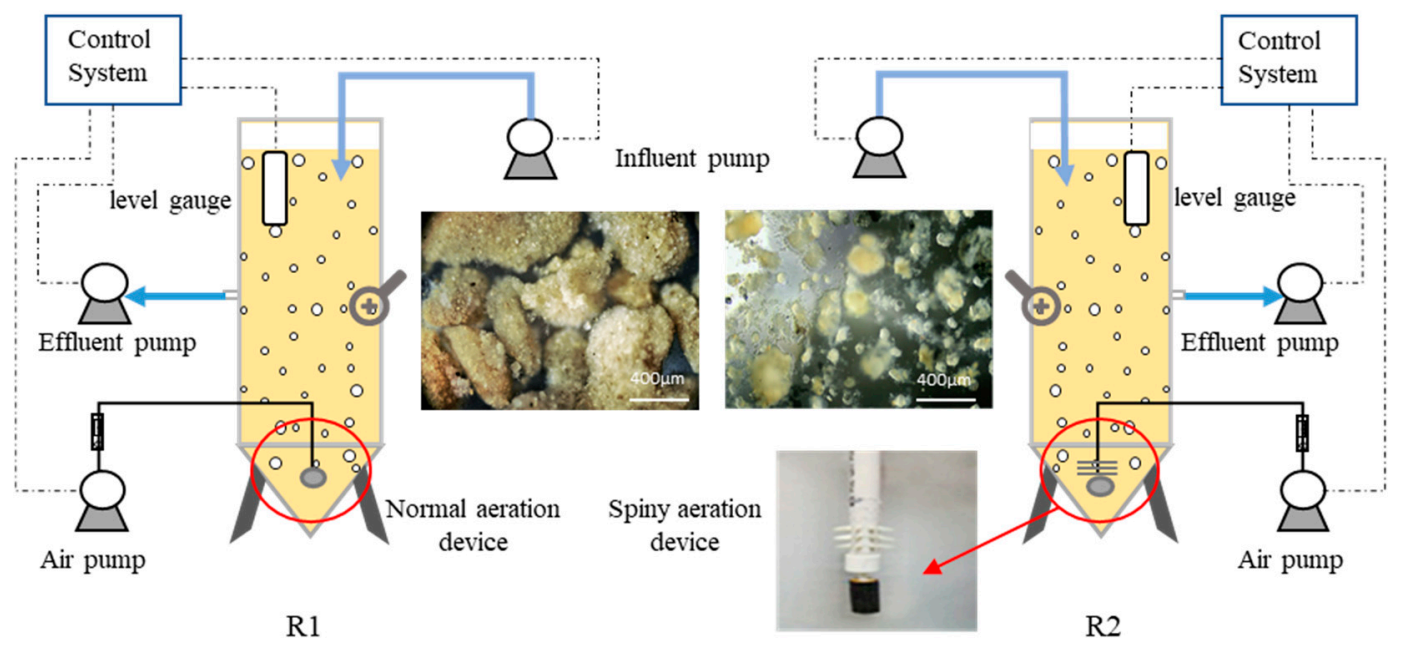

Figure 1. Schematic diagram of the sequencing batch reactors (SBRs).

\subsubsection{Pilot-Scale Sequencing Batch Reactors}

A spiny aeration device was installed at the bottom of an AGS pilot-scale SBR system [21] (Figure 2). The system could dispose $120 \mathrm{~m}^{3} / \mathrm{d}$ wastewater from a town. The pilot-scale system was composed of two parallel columns (diameter of $2 \mathrm{~m}$, height of $6 \mathrm{~m}$, and $\mathrm{H} / \mathrm{D}$ of 2.5 ) with $31.4 \mathrm{~m}^{3}$ working volume and $50 \%$ volumetric exchange ratio. One period included fill $(40 \mathrm{~min})$, aeration $(120 \mathrm{~min})$, settling $(60 \mathrm{~min})$, and discharge $(20 \mathrm{~min})$. The system was operated continuously for more than 400 days. The agnail aeration device and air pipe layout were shown in Figure 2.

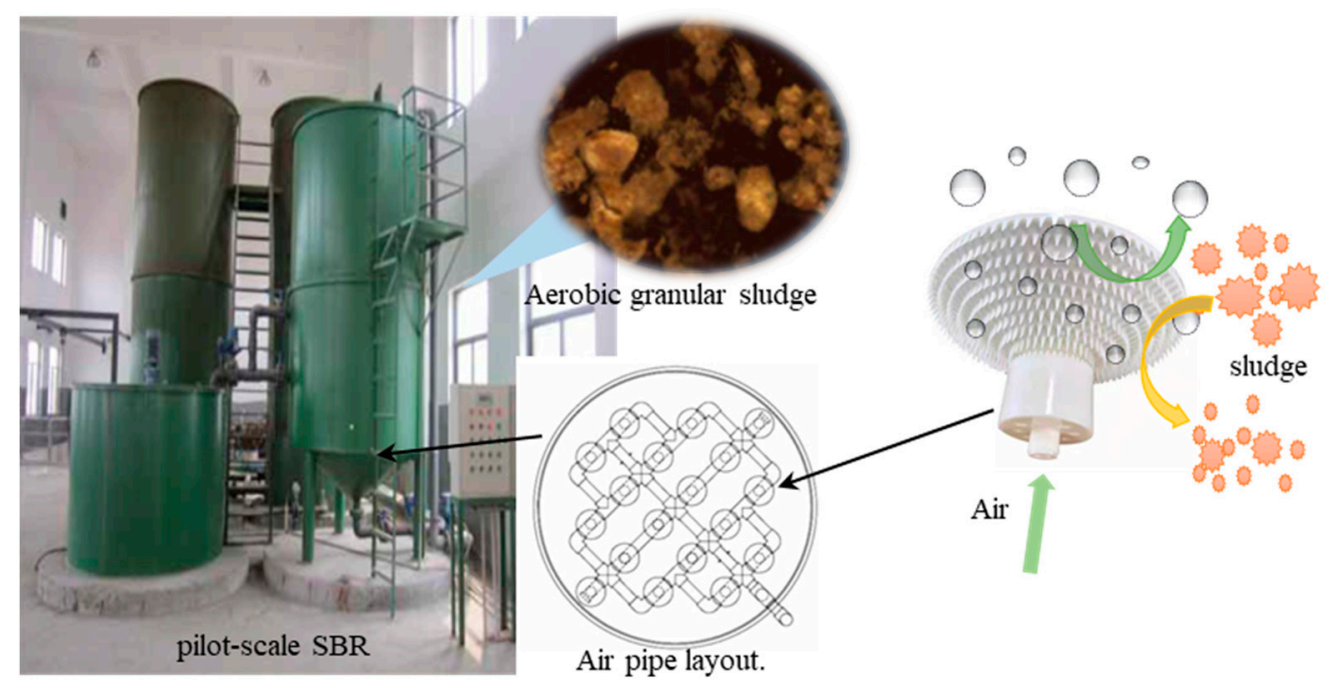

Figure 2. System of the pilot-scale reactor.

\subsection{Analytical Methods}

The $\mathrm{SVI}_{30}$ and MLSS were measured periodically. Liquid samples in the feed and effluent were filtered periodically using $0.45-\mu \mathrm{m}$ filters. $\mathrm{COD}_{\mathrm{Cr}}$ was measured by fast digestion-spectrophotometric method and $\mathrm{NH}_{4}{ }^{+}-\mathrm{N}$ was measured by Nesslerization. All these methods were in accordance with standard methods [22]. Samples were taken from the reactor at predetermined time intervals for analysis. The $\mathrm{pH}$ was monitored using a $\mathrm{pH}$ meter (PHS-3D, Shanghai). The morphology of sludge was observed by an Olympus CX31 microscope and a digital camera (Canon EOS 30D). The size of granules was analyzed by an image analysis system (Image-Pro Plus 6.0, Media Cybernetics, Rockville, MD, USA). The system reported the average length of diameters measured at $5^{\circ}$ intervals around the 
centroid of each object and then output the statistics. The X-ray fluorescence (XRF) analysis was performed using ARL ADVANT'X IntelliPower TM 4200 (Thermo Fisher, Waltham, MA, USA).

Three sludge samples acquired from the inoculation sludge and sludge from two bioreactors were freeze-dried for nucleotide extraction. Microbial DNA was extracted from AGS samples using the E.Z.N.A. ${ }^{\circledR}$ Mag-Bind Soil DNA Kit (Omega Bio-tek, Norcross, GA, USA) in accordance with the manufacturer's protocols. The final DNA concentration and purification were determined by NanoDrop 2000 UV-vis spectrophotometer (Thermo Scientific, Wilmington, DE, USA), and DNA quality was checked by $1 \%$ agarose gel electrophoresis. The V3-V4 hypervariable regions of the bacteria 16S rRNA gene were amplified with primers 341F and 805R by thermocycle PCR system (GeneAmp 9700, ABI, Waltham, MA, USA). The PCR reactions were conducted using the following program: 3 min of denaturation at $94{ }^{\circ} \mathrm{C} ; 20$ cycles of $30 \mathrm{~s}$ at $94{ }^{\circ} \mathrm{C}, 20 \mathrm{~s}$ at $45^{\circ} \mathrm{C}$ and $30 \mathrm{~s}$ at $65^{\circ} \mathrm{C}$; 20 cycles of $20 \mathrm{~s}$ at $94{ }^{\circ} \mathrm{C}, 20 \mathrm{~s}$ at $55^{\circ} \mathrm{C}$ and $30 \mathrm{~s}$ at $72{ }^{\circ} \mathrm{C}$; and a final extension at $72{ }^{\circ} \mathrm{C}$ for 5 min. The PCR product was recovered using an AxyPrep DNA Gel Extraction Kit (AXYGEN, Corning, NY, USA) and quantified with a QuantiFluor TM -ST system. The highthroughput sequencing of PCR products was performed using the Illumina MiSeq platform of Majorbio Bio-Pharm Technology Co., Ltd. (Shanghai, China). The operational taxonomic units (OTUs) were clustered with a distance limit of 0.03, using Usearch. Microbial alpha diversity indices such as Shannon, Simpson, Chao, and the abundance-based coverage estimator (ACE) were analyzed using the MOTHUR program. The RDP Classifier with a confidence threshold of $70 \%$ was used to classify effective sequences into different taxonomy units, while the community composition was analyzed at different taxonomy levels.

\section{Results}

\subsection{Comparison of Sludge Characteristics \\ 3.1.1. Sludge Particle Size}

The variation of sludge particle size is shown in Figure 3. The same flocculent sludge was inoculated into the R1 and R2 bioreactors, respectively, and the MLSS in both reactors after inoculation was around $1750 \mathrm{mg} / \mathrm{L}$. After 15 days' operation, a few small particles began to appear in both reactors, but the sludge was still mainly flocs. The particle size and the number of granules in R1 were both slightly larger than those in R2. After 23 days of operation, aerobic sludge in R1 began to granulate, while AGS appeared in R2 six days later than in R1. On the thirty-fifth day, the granular sludge in both R1 and R2 had grown in size, but there was still plenty of flocculent sludge. After 62 days, the sludge in R1 was basically granular with a clear profile. The granular sludge in R2 was also clear but it still contained some flocculent sludge with a prominently smaller particle size than that in R1. The average particle size of the granular sludge was $285 \mu \mathrm{m}$ in R1 and $190 \mu \mathrm{m}$ in R2. The particle size distribution (PSD) was mainly within the range of $0-0.5 \mathrm{~mm}$ in SBR1 and SBR2. On day 62 , and in SBR1, the PSD $<0.2 \mathrm{~mm}$ was $10.7 \%$, while those at $0.2-0.5 \mathrm{~mm}$ reached $89.3 \%$, respectively. In SBR2, the PSD $<0.2 \mathrm{~mm}$ was $36.2 \%$ and $0.2-0.4 \mathrm{~mm}$ was $63.8 \%$. 

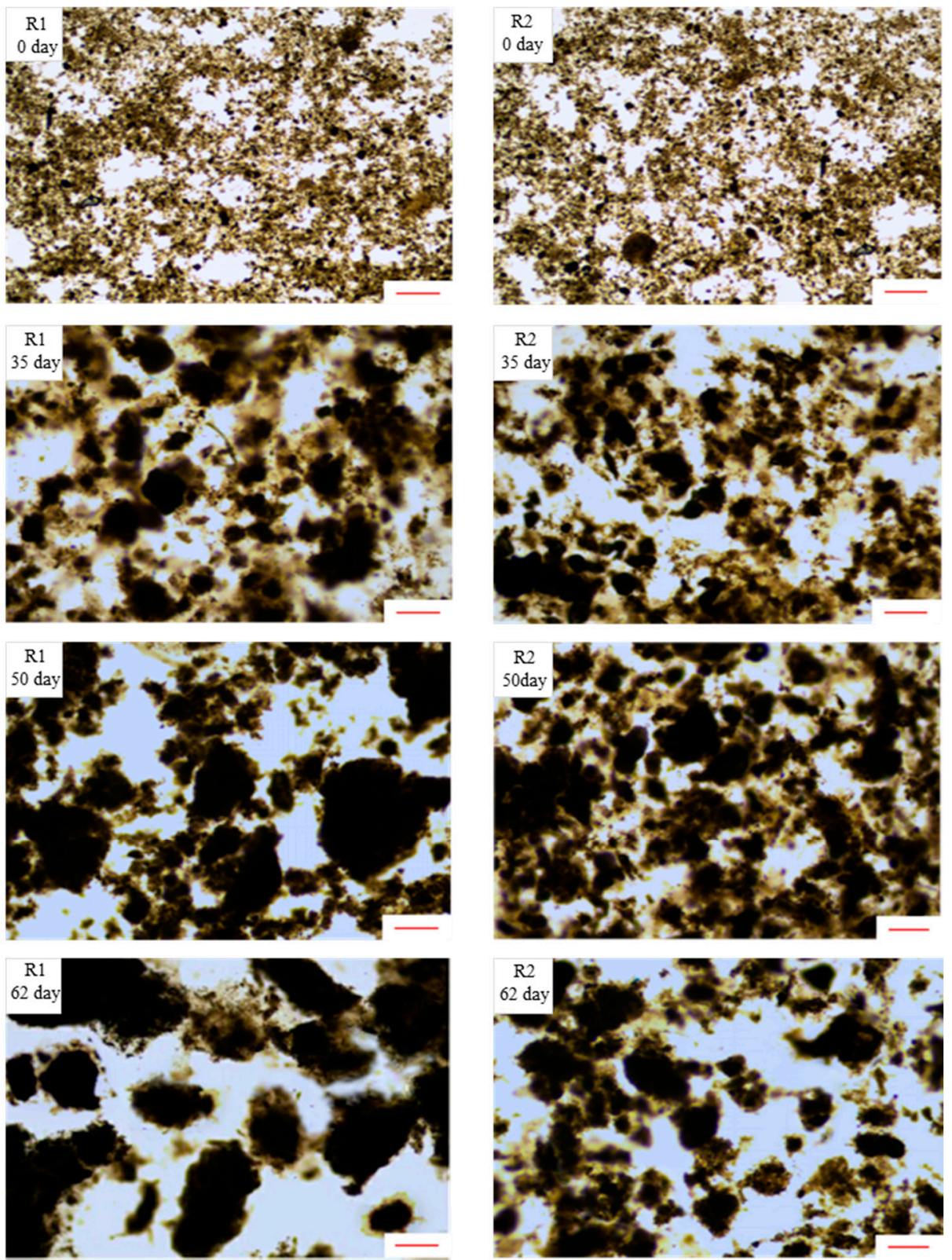

Figure 3. Variations in the morphology of sludge (scale bar: $200 \mu \mathrm{m}$ ).

\subsubsection{Sludge Sedimentation}

The initial MLSS was 1750 and SVI was $73 \mathrm{~mL} / \mathrm{g}$ for both SBR systems in the first phase. On the whole, the MLSS in both reactors indicated an increasing trend while SVI indicated a decreasing trend, with both the MLSS and SVI in R1 being lower than those in R2 (Figure 4). In the first 4 days, due to the short settling time of only 5 min, sludge with poor settling performance was discharged from the bioreactor. In consequence, the MLSS in R1 and R2 decreased from 1750 to 1733 and $1730 \mathrm{mg} / \mathrm{L}$, respectively. In the following 4 days, MLSS increased to 1819 and $1967 \mathrm{mg} / \mathrm{L}$ in R1 and R2, respectively. On the eighth day, the MLSS decreased both in R1 and R2, and the SVI increased on account of the deterioration of the sludge settling performance. On the twenty-fifth day, the MLSS in R1 and R2 manifested an increasing trend and augmented to 2003 and $2396 \mathrm{mg} / \mathrm{L}$, respectively. After 25 days, the MLSS in R1 sustained growth in a continuously stable state at $2400 \mathrm{mg} / \mathrm{L}$. The MLSS in R2 decreased from 2396 to $2105 \mathrm{mg} / \mathrm{L}$ from day 25 to 45 . After 45 days, the MLSS in R2 began to increase, and on the sixty-fifth day, it maintained stable at about $2450 \mathrm{mg} / \mathrm{L}$. The SVI in R1 and R2 increased to 100 and $92 \mathrm{~mL} / \mathrm{g}$, respectively, in the first 13 
days of operation. After 13 days, the SVI in R1 continued to decrease and maintained stable at about $45 \mathrm{~mL} / \mathrm{g}$ after 65 days of operation, while the SVI in R2 increased to $80 \mathrm{~mL} / \mathrm{g}$ after 35 days of operation. After 35 days, the SVI in R2 began to decrease and was basically stable at $50 \mathrm{~mL} / \mathrm{g}$ on the sixty-fifth day. The SVI of R2 decreased more slowly than that of $\mathrm{R} 1$, and eventually the SVI of the granular sludge in R2 was slightly higher than that in R1.
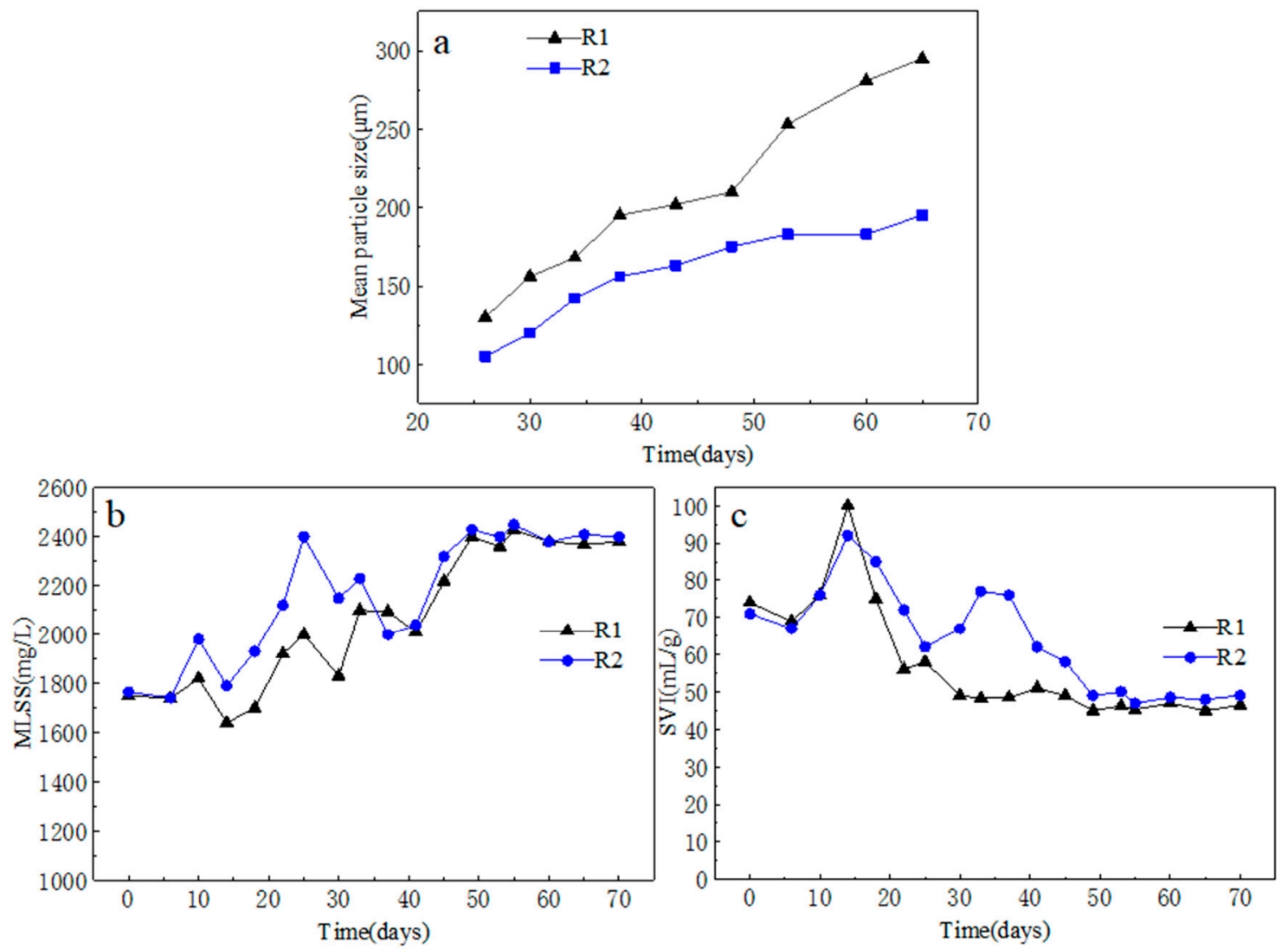

Figure 4. Variations in the mean particle size, mixed liquor suspended solids (MLSS), and sludge volume index (SVI) of sludge. ((a) mean particle size; (b) MLSS, (c) and SVI).

\subsubsection{Microbial Community Analysis}

The microbial community was analyzed through high-throughput sequencing. As shown in Figure 5, the results indicated that two bacterial phyla, Proteobacteria and Bacteroidetes, were the most abundant in the inoculated sludge, accounting for $46.45 \%$ and $31.74 \%$ of the total sequence in the inoculated sludge respectively, followed by Firmicutes, Deinococcus-Thermus, Chloroflexi, Planctomycetes, Acidobacteria, and Gemmatimonadetes, accounting for $3.55 \%, 3.4 \%, 2.62 \%, 2.33 \%, 2.23 \%$, and $2.01 \%$ in the inoculated sludge, respectively. The microbial community of R1 sludge was mainly constituted by Proteobacteria and Bacteroidetes, accounting for $91.98 \%$ and $6.27 \%$ of the total sequence, respectively. R2 was similar to R1 with Proteobacteria and Bacteroidetes, accounting for $85.86 \%$ and $10.95 \%$ of the total sequences, respectively. Compared with inoculated sludge, the amount of Proteobacteria in R1 and R2 rolled up, Bacteroidetes decreased, and other bacteria phyla also decreased. 


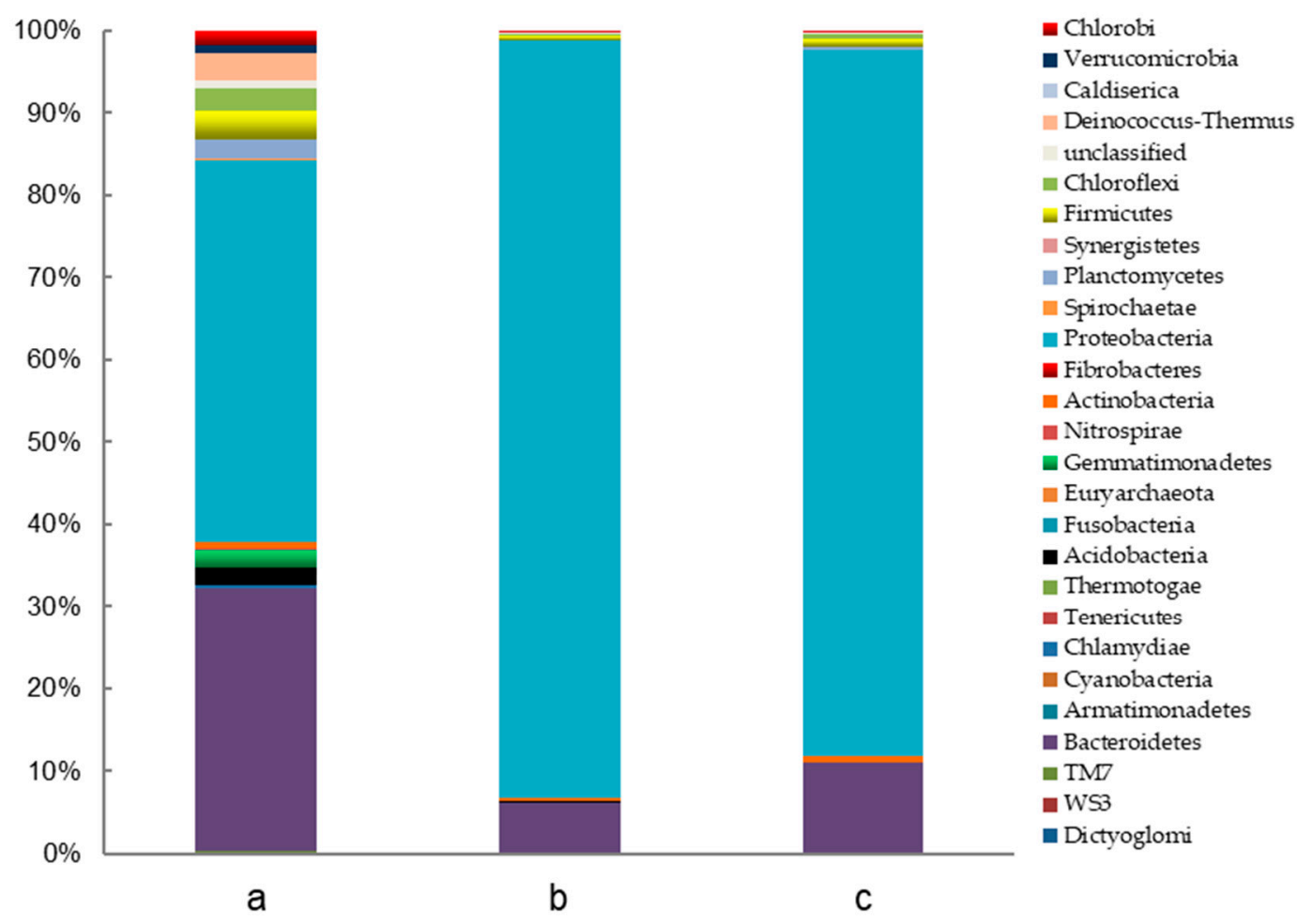

Figure 5. Distribution of microorganisms at phyla level ((a) inoculated sludge; (b) sludge of R1; (c) sludge of R2).

\subsubsection{The X-ray Fluorescence Analysis of Sludge}

The XRF was adopted to analyze the element composition of feed water and AGS. It showed that raw water contains large amounts of $\mathrm{Na}, \mathrm{Cl}, \mathrm{Ca}, \mathrm{Mg}$, and $\mathrm{P}$. The AGS accumulates elements such as $\mathrm{Fe}, \mathrm{Ca}, \mathrm{Mg}$, and P. As shown in Figure 6a, influent samples were measured for the mass fraction of each element in the water and the mass fraction of the water, and the proportion of each element in the total solute mass was obtained by conversion. It can be seen from the figure that the proportion of the element $\mathrm{Na}$ in the feed water is $38 \%, 27 \%$ for $\mathrm{Cl}$, followed by $11 \%, 11 \%, 5 \%, 0.6 \%$, and $0.3 \%$ for $\mathrm{P}, \mathrm{Mg}, \mathrm{Ca}$, $\mathrm{Si}$, and $\mathrm{Fe}$, respectively, and $7.1 \%$ for the other elements. The element distribution of the AGS in R1 was shown in Figure 6b. Ca and Fe account for a larger proportion, 11.6\% and $10.4 \%$, respectively, followed by $\mathrm{Na}, \mathrm{Cl}, \mathrm{Si}, \mathrm{P}, \mathrm{Mg}, \mathrm{Al}$, and other elements as $5.6 \%, 3.4 \%$, $1.3 \%, 1.2 \%, 0.9 \%, 0.4 \%$, and $65.2 \%$. The element distribution of AGS in R2 was shown in Figure $6 \mathrm{c}$. The elements with a larger proportion were $\mathrm{Fe}, \mathrm{Na}$, and $\mathrm{Ca}$ at $8.4 \%, 7 \%$, and $6 \%$, followed by $\mathrm{Cl}, \mathrm{Si}, \mathrm{P}, \mathrm{Mg}, \mathrm{Al}$, and other elements at $4.4 \%, 1.2 \%, 1 \%, 0.8 \%, 0.3 \%$, and $70.9 \%$, respectively. Comparing the elements in feed water and AGS, it could be seen that Fe and $\mathrm{Ca}$ were heavily enriched in the granular sludge. The content of elements Fe and $\mathrm{Ca}$ in R1 was greater than that in $\mathrm{R} 2$, but the content of elements $\mathrm{Na}$ and $\mathrm{Cl}$ was less than that in $\mathrm{R} 2$. The proportions of other elements were similar in these two reactors. 

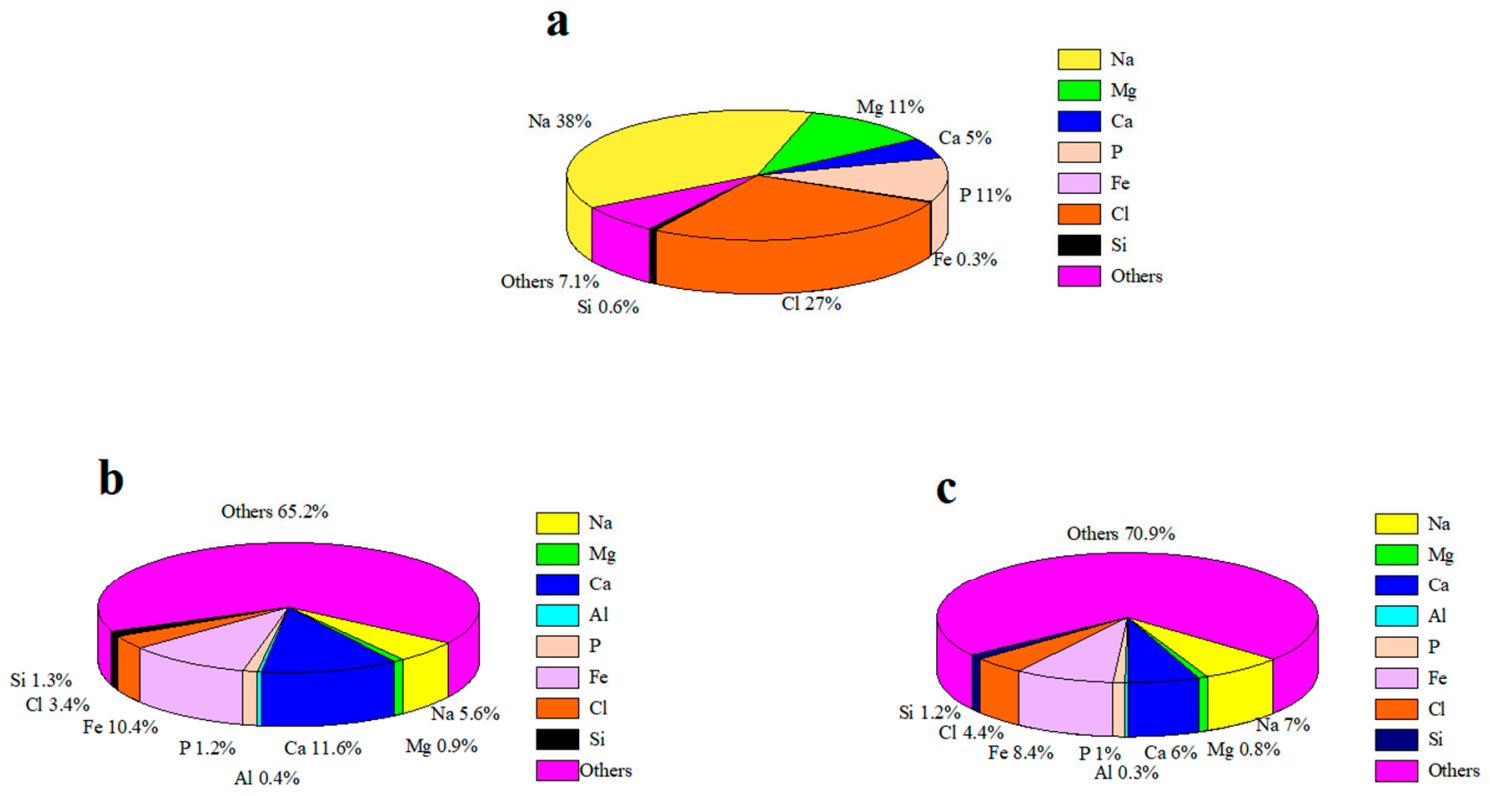

Figure 6. Elemental composition ((a) influent; (b) sludge of R1; (c) sludge of R2).

\subsection{Pollutant Removal Performance}

The removal effects of $\mathrm{COD}$ and $\mathrm{NH}_{4}{ }^{+}-\mathrm{N}$ were shown in Figure $7 \mathrm{a}, \mathrm{b}$. The concentration of COD in the influent of R1 and R2 had maintained at 500-800 mg/L, while that in effluent had been kept below $300 \mathrm{mg} / \mathrm{L}$ since the outset of operation, and it stabilized at less than $200 \mathrm{mg} / \mathrm{L}$ and the removal (\%) reached $79 \%$ after 50 days of operation. The concentration of $\mathrm{NH}_{4}{ }^{+}-\mathrm{N}$ in the feed of $\mathrm{R} 1$ and $\mathrm{R} 2$ was 110-160 mg/L. After 49 days, this figure in the effluent water was basically less than $70 \mathrm{mg} / \mathrm{L}$. The concentration of COD and $\mathrm{NH}_{4}{ }^{+}-\mathrm{N}$ in the effluent met the discharge standard [23] of water pollutants for the leather- and fur-making industry in China. In general, the COD and $\mathrm{NH}_{4}{ }^{+}-\mathrm{N}$ removal effect of R1 and R2 did not differ from each other significantly; namely, spiny aeration did not contribute to the efficiency of the pollutant removal.

After aerobic sludge granulation, the contamination removal effect of R1 and R2 in one cycle was analyzed, as shown in Figure 7c,d. The situation of R2 was similar to R1 in that the concentration of COD and $\mathrm{NH}_{4}{ }^{+}-\mathrm{N}$ declined rapidly in both reactors within a short period of time, with a slightly smaller decrease of COD and a slightly larger decrease in $\mathrm{NH}_{4}{ }^{+}-\mathrm{N}$ at the first $5 \mathrm{~h}$ in $\mathrm{R} 2$ than in $\mathrm{R} 1$. The $\mathrm{pH}$ of both $\mathrm{R} 1$ and $\mathrm{R} 2$ was constantly rising, with a $\mathrm{pH}$ of 7.83 in the influent and 8.63 in the effluent. 

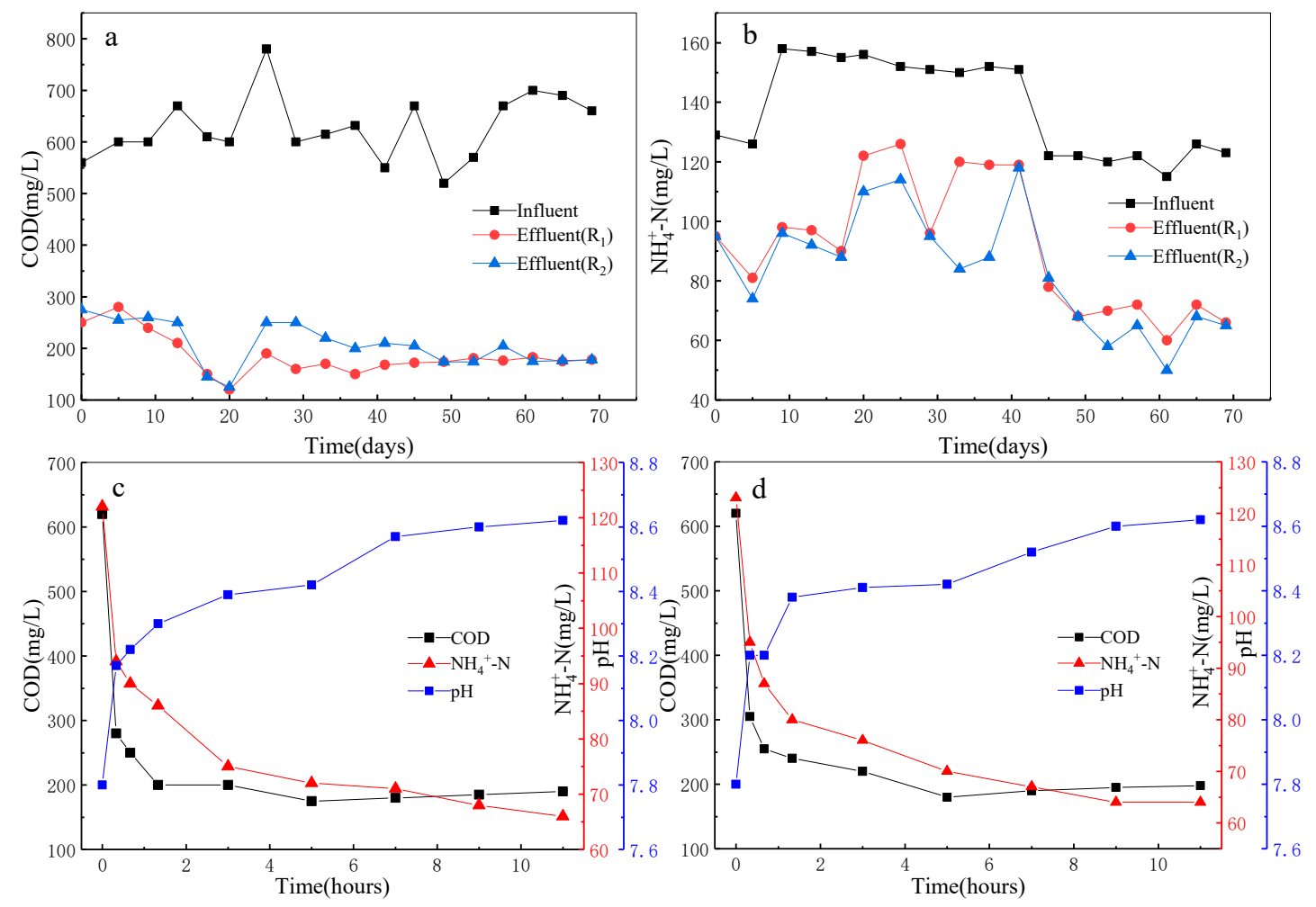

Figure 7. Performance of the reactors ((a) chemical oxygen demand (COD); (b) ammonia nitrogen $\left(\mathrm{NH}_{4}{ }^{+}-\mathrm{N}\right),(\mathbf{c}) \mathrm{COD}$, $\mathrm{NH}_{4}{ }^{+}-\mathrm{N}$, and $\mathrm{pH}$ of $\mathrm{R} 1$; (d) $\mathrm{COD}, \mathrm{NH}_{4}{ }^{+}-\mathrm{N}$, and $\mathrm{pH}$ of $\left.\mathrm{R} 2\right)$.

\subsection{An Attempt at the Pilot-Scale System}

After 7 days, small aerobic granules could be observed. On the twentieth day, loose sludge began to conglomerate into lumps. On the fiftieth day, there was mainly AGS with a compact structure and irregular outline in the reactor. As the reactor continued to operate, the average particle size of granular sludge remained at $300 \mu \mathrm{m}$ and the SVI was $43 \mathrm{~mL} / \mathrm{g}$ in the end. The pilot-scale reaction was operated continuously for more than 400 days and maintained high removal efficiencies for pollutants. The removal of COD was maintained at about $88 \%$ and almost all the $\mathrm{NH}_{4}{ }^{+}-\mathrm{N}$ was removed. It could be seen that the particle size of AGS in SBR can be effectively restricted by using the spiny aeration tray, which indicated that the spiny aeration device plays an important role in restricting the particle size in the pilot-scale SBR.

\section{Discussion}

Through the analysis of sludge characteristics, the spiny aeration device effectively controlled the particle size of aerobic sludge by collision and abrasion. In the process of aeration, the granular sludge would collide with the agnail on the aeration device, and then the sharp agnail would abrade large particles, causing them to be broken (Figure 2). The granular sludge with a larger particle size was more likely to be in the lower half of the reactor so that it was more likely to come into contact with the agnail. At the same time, most of the small particles could smoothly pass through the space between agnails with small probability of being punctured.

Due to physical fragmentation, the sedimentation of the sludge showed no significant change in both bioreactors. The removal (\%) of COD and $\mathrm{NH}_{4}{ }^{+}-\mathrm{N}$ in these two bioreactors did not differ from each other greatly.

In this experiment, the Proteobacteria was abundant and prior in the AGS of tannery wastewater treatment. This result was similar to the research of Zhao et al. [24] and Huang et al. [25]. It is reported that Proteobacteria is common in AGS and can produce excessive extracellular polymers to promote flocculation of flocculent sludge and formation of AGS. 
In addition, Proteobacteria have the ability to degrade COD and nitrogen. The number of Proteobacteria in AGS was much more than that in inoculated sludge, which indicated that Proteobacteria played an important role in the granulation of AGS. The analysis of biological composition displayed that the proportion of Proteobacteria decreased slightly in the R2. Most members of Proteobacteria are facultatively or obligately anaerobic. The larger anaerobic zone is formed in the bigger particle size of the sludge [26]. This indicated that the particle size of sludge in the R2 was effectively restricted.

This experiment result of the X-ray fluorescence analysis indicates that the larger particle size of the granular sludge was enriched with more $\mathrm{Fe}$ and $\mathrm{Ca}$, which was consistent with the study of Liu et al. [21], The ash in AGS contained more calcium salts (mainly calcium carbonate), and the content of calcium carbonate precipitate increased with the increase of the particle size of the granular sludge within a certain size range [27]. Other research and literature suggested that a large accumulation of calcium would undermine the biological activity [28].

Therefore, it could be seen that the particle size of AGS in SBR was effectively restricted by using the spiny aeration device, which indicated that the spiny aeration device played an important role in restricting the particle size in the SBR. Long et al. [20] enhanced the stable operation of AGS in pilot-scale SBR by manually sieving to obtain the 2000-3000 $\mu \mathrm{m}$ granular sludge and returning it to the reactor to increase their proportion. Sieving manually can completely retain the structure of the AGS, but the high cost and low efficiency of this method make it unsuitable for engineering applications. Compared with the existing method of particle size control, using the spiny aeration device might damage the particle structure in some way, but its operability is suitable for engineering application. In addition, using the spiny aeration device did not exert influence on the removal (\%) of $\mathrm{COD}$ and $\mathrm{NH}_{4}{ }^{+}-\mathrm{N}$ in the system.

\section{Conclusions}

A bioreactor with the spiny aeration device could effectively restrict the particle size of the AGS. The oversized AGS was more likely to collide and abrase with the spines and air bubbles. However, the spiny aeration device made no difference in the pollutant removal and sludge characteristics. By adding the spiny aeration device in the pilot-scale SBR system, the average particle size of AGS could be effectively restricted at about $300 \mu \mathrm{m}$.

Supplementary Materials: The following are available online at https:/ /www.mdpi.com/2227-971 7/9/2/374/s1, Table S1: Basic climatic conditions of Hangzhou.

Author Contributions: Conceptualization, H.F., H.Y., and J.L.; methodology, H.F. and H.Y.; software, H.F. and H.Y.; validation, H.F., Z.P., and J.S.; data curation, H.F. and H.Y.; writing-original draft preparation, H.F.; writing - review and editing, H.F., Z.P., and J.S.; funding acquisition, J.L. supervision, J.L.; project administration, J.L. All authors have read and agreed to the published version of the manuscript.

Funding: The research was funded by the Major Science and Technology Program for Water Pollution Control and Treatment (2017ZX07201003), the Zhejiang Key Research and Development Program (no. 2018C03006).

Institutional Review Board Statement: "Not applicable" for studies not involving humans or animals.

Informed Consent Statement: "Not applicable" for studies not involving humans.

Data Availability Statement: Data sharing not applicable.

Acknowledgments: This work was supported by the Major Science and Technology Program for Water Pollution Control and Treatment (2017ZX07201003), the Zhejiang Key Research and Development Program (no. 2018C03006).

Conflicts of Interest: The authors declare no conflict of interest. 


\section{References}

1. De Kreuk, M.K.; Kishida, N.; Van Loosdrecht, M.C.M. Aerobic granular sludge-State of the art. Water Sci. Technol. 2007, 55, 75-81. [CrossRef]

2. Bhunia, P.; Ghangrekar, M. Required minimum granule size in UASB reactor and characteristics variation with size. Bioresour. Technol. 2007, 98, 994-999. [CrossRef] [PubMed]

3. Mishima, K.; Nakamura, M. Self-Immobilization of Aerobic Activated Sludge-A Pilot Study of the Aerobic Upflow Sludge Blanket Process in Municipal Sewage Treatment. Water Sci. Technol. 1991, 23, 981-990. [CrossRef]

4. Zhang, Q.; Hu, J.; Lee, D.-J. Aerobic granular processes: Current research trends. Bioresour. Technol. 2016, 210, 74-80. [CrossRef] [PubMed]

5. Lotito, A.M.; De Sanctis, M.; Di Iaconi, C.; Bergna, G. Textile wastewater treatment: Aerobic granular sludge vs activated sludge systems. Water Res. 2014, 54, 337-346. [CrossRef]

6. Rosman, N.H.; Anuar, A.N.; Othman, I.; Harun, H.; Sulong, M.Z.; Elias, S.H.; Hassan, M.A.H.M.; Chelliapan, S.; Ujang, Z. Cultivation of aerobic granular sludge for rubber wastewater treatment. Bioresour. Technol. 2013, 129, 620-623. [CrossRef]

7. Corsino, S.F.; Di Biase, A.; Devlin, T.R.; Munz, G.; Torregrossa, M.; Oleszkiewicz, J.A. Effect of extended famine conditions on aerobic granular sludge stability in the treatment of brewery wastewater. Bioresour. Technol. 2017, 226, 150-157. [CrossRef]

8. Chen, C.; ming, J.; Yoza, B.A.; Liang, J.; Li, Q.X.; Guo, H.; Liu, Z.; Deng, J.; Wang, Q. Characterization of aerobic granular sludge used for the treatment of petroleum wastewater. Bioresour. Technol. 2019, 271, 353-359. [CrossRef] [PubMed]

9. Liu, W.; Wu, Y.; Zhang, S.; Gao, Y.; Jiang, Y.; Horn, H.; Li, J. Successful granulation and microbial differentiation of activated sludge in anaerobic/anoxic/aerobic (A2O) reactor with two-zone sedimentation tank treating municipal sewage. Water Res. 2020, 178, 115825. [CrossRef]

10. Guo, T.; Ji, Y.; Zhao, J.; Horn, H.; Li, J. Coupling of Fe-C and aerobic granular sludge to treat refractory wastewater from a membrane manufacturer in a pilot-scale system. Water Res. 2020, 186, 116331. [CrossRef]

11. Li, J.; Ding, L.-B.; Cai, A.; Huang, G.-X.; Horn, H. Aerobic Sludge Granulation in a Full-Scale Sequencing Batch Reactor. BioMed Res. Int. 2014, 2014, 1-12. [CrossRef] [PubMed]

12. Pronk, M.; De Kreuk, M.; De Bruin, B.; Kamminga, P.; Kleerebezem, R.; Van Loosdrecht, M. Full scale performance of the aerobic granular sludge process for sewage treatment. Water Res. 2015, 84, 207-217. [CrossRef]

13. Franca, R.D.; Pinheiro, H.M.; Van Loosdrecht, M.C.; Lourenço, N.D. Stability of aerobic granules during long-term bioreactor operation. Biotechnol. Adv. 2018, 36, 228-246. [CrossRef] [PubMed]

14. Jungles, M.K.; Figueroa, M.; Morales, N.; Del Río, Á.V.; Da Costa, R.H.R.; Campos, J.L.; Mosquera-Corral, A.; Méndez, R. Start up of a pilot scale aerobic granular reactor for organic matter and nitrogen removal. J. Chem. Technol. Biotechnol. 2011, 86, 763-768. [CrossRef]

15. Farooqi, I.; Basheer, F. Treatment of Adsorbable Organic Halide (AOX) from pulp and paper industry wastewater using aerobic granules in pilot scale SBR. J. Water Process. Eng. 2017, 19, 60-66. [CrossRef]

16. Lee, D.-J.; Chen, Y.-Y.; Show, K.-Y.; Whiteley, C.G.; Tay, J.-H. Advances in aerobic granule formation and granule stability in the course of storage and reactor operation. Biotechnol. Adv. 2010, 28, 919-934. [CrossRef]

17. Toh, S.K.; Tay, J.H.; Moy, B.Y.P.; Ivanov, V.; Tay, S.T.L. Size-effect on the physical characteristics of the aerobic granule in a SBR. Appl. Microbiol. Biotechnol. 2003, 60, 687-695. [CrossRef] [PubMed]

18. Zhu, T.; Xu, B.; Wu, J. Experimental and mathematical simulation study on the effect of granule particle size distribution on partial nitrification in aerobic granular reactor. Biochem. Eng. J. 2018, 134, 22-29. [CrossRef]

19. Verawaty, M.; Tait, S.; Pijuan, M.; Yuan, Z.; Bond, P.L. Breakage and growth towards a stable aerobic granule size during the treatment of wastewater. Water Res. 2013, 47, 5338-5349. [CrossRef]

20. Long, B.; Xuan, X.; Yang, C.; Zhang, L.; Cheng, Y.; Wang, J. Stability of aerobic granular sludge in a pilot scale sequencing batch reactor enhanced by granular particle size control. Chemosphere 2019, 225, 460-469. [CrossRef]

21. Yang, H.G.; Li, J.; Ding, L.B.; Chen, T.; Huang, G.X.; Shen, J.Y.; Liu, J. A case for aerobic sludge granulation: From pilot to full scale. J. Water Reuse Desalination 2015, 6, 188-194. [CrossRef]

22. Eaton, A.; Clesceri, L.S.; Rice, E.W.; Greenberg, A.E.; Franson, M. APHA: Standard Methods for the Examination of Water and Wastewater; Centennial Edition; APHA, AWWA, WEF: Washington, DC, USA, 2005.

23. Ministry of Ecological Environment of the People's Republic of China; State Administration for Market Regulation. Discharge Standard of Water Pollutants for Leather and Fur Making Industry. Available online: http:/ /www.mee.gov.cn/ywgz/fgbz/bz/ bzwb / shjbh/swrwpfbz/201312/t20131227_265766.shtml (accessed on 11 December 2020).

24. Zhao, Y.; Huang, J.; Zhao, H.; Yang, H. Microbial community and N removal of aerobic granular sludge at high COD and N loading rates. Bioresour. Technol. 2013, 143, 439-446. [CrossRef] [PubMed]

25. Huang, W.; Li, B.; Zhang, C.; Zhang, Z.; Lei, Z.; Lu, B.; Zhou, B. Effect of algae growth on aerobic granulation and nutrients removal from synthetic wastewater by using sequencing batch reactors. Bioresour. Technol. 2015, 179, 187-192. [CrossRef] [PubMed]

26. Han, Y.; Liu, J.; Guo, X.; Li, L. Micro-environment characteristics and microbial communities in activated sludge flocs of different particle size. Bioresour. Technol. 2012, 124, 252-258. [CrossRef] [PubMed] 
27. Liu, Y.-Q.; Lan, G.-H.; Zeng, P. Size-dependent calcium carbonate precipitation induced microbiologically in aerobic granules. Chem. Eng. J. 2016, 285, 341-348. [CrossRef]

28. Ren, T.-T.; Liu, L.; Sheng, G.-P.; Liu, X.-W.; Yu, H.-Q.; Zhang, M.-C.; Zhu, J.-R. Calcium spatial distribution in aerobic granules and its effects on granule structure, strength and bioactivity. Water Res. 2008, 42, 3343-3352. [CrossRef] 